\title{
Análisis del bajón como banquete del cínico
}

\section{The analysis of the 'bajón' as a banquet for the cynical}

CONSUELO LLANAS GÁMEZ

Universidad Iberoamericana

Ciudad de México, México

consuelollanas@gmail.com

Artículo de investigación

Recepción: 11 de enero de 2020

Aceptación: 26 de marzo de 2020

\section{Como citar este artículo}

Llanas.C.(2019). Análisis del bajón como banquete del cínico. Sosquua1(2), pp. 26-34. Recuperado a partir de: http://cipres. sanmateo.edu.co/index.php/sosquua

"Una cultura neopagana que no cree en una vida después de la muerte tiene consiguientemente que buscarla antes de ésta". -Peter Sloterdijk

"Convidar a alguien equivale a encargarse de su felicidad en tanto que esté con nosotros".

-Brillat-Savarin 


\section{Resumen:}

El presente artículo analiza el 'bajón' como una propuesta de un banquete cínico; construido a partir de lo más común y necesario para el Hombre: el hambre. Además, utiliza la precariedad como un símil de palabras que muestra los sujetos concretos. Esto, como posibilidad a la formación de una comunidad en la que predomine el encuentro con el otro como un lazo político de amistad y reconocimiento que aparece y desaparece con el banquete.

Palabras Clave: Bajón; cinismo; comunidad; político.

\section{Abstract:}

The present paper analyze the 'bajón' as a proposal for a cynical banquet which is constructed from the most common and necessary thing for men: the hunger. Besides, it uses the precariousness as a simile of words that show the concrete subjects. This, as a possibility to the formation of a community in which the encounter with the other predominates as a political bond of friendship and recognition, which appears and disappears with the banquet.

Keyword: Bajón; cynism; community; political.

\section{Introducción}

Este análisis surge desde mi propia experiencia como estudiante foránea becaria. Durante este tiempo he tenido la experiencia de la precariedad para cubrir mis necesidades básicas, como lo es el alimento. Si bien, la práctica del 'bajón' (comida gratis) era algo que con anterioridad ya había realizado; el hecho de tener que realizarlo desde la falta de más opciones es lo que le dio un matiz distinto. Fue en un momento preciso que caí en cuenta de la posibilidad de una comunidad con ello. 
La unidad académica de la que soy parte está poblada de estudiantes que en su mayoría tienen sus necesidades cubiertas; hay diversos centros para comprar y consumir alimento. De igual manera, existen máquinas a la disposición de un tarjeta o dinero, por lo que de alguna forma la falta de dinero para realizar estas transacciones me hacía quedar en un espacio de exclusión; era yo y mi necesidad de alimento como recordatorio de exposición ante mi propia condición de viviente, una condición exclusiva e intransmisible.

A partir de lo anterior, después de una clase un compañero foráneo y yo, encontramos un banquete de galletas a punto de ser recogido sin ser tocado. Nos acercamos y, a través de un pequeño intercambio de palabras con la encargada de tal banquete, tuvimos acceso a él. Así, empezamos a discutir sobre unos carteles presentes que aludían a la actividad llevada a cabo; consumimos información y alimento de forma gratuita, haciendo uso de un intercambio entre una breve necesidad común que se tenía: el hambre

De ese momento surge este análisis; en esa necesidad común brotó una sensación de una comunidad otra, que parecía dar un espacio de inclusión a la unidad académica. Un espacio desde los otros, aquellos que habitan y merodean entre los pasillos buscando actividades con alimento gratis.

\section{¿Qué es el bajón?}

Si bien, anteriormente se mencionaron unas claves para entender la palabra 'bajón', es necesario que me detenga un poco más en ella. El bajón' puede entenderse como una forma coloquial de nombrar la comida que se consigue de forma gratis o a un bajo costo, pero, logra 'calmar' el hambre. El uso de la palabra corresponde a un sector joven de la sociedad, por lo regular de condiciones precarias, donde la calma del hambre suele ser un obstáculo a enfrentarse, como una misión $n^{2}$ que hay que emprender por día.

Aquí me referiré sólo a la primera acepción de la palabra bajón, la forma gratis de conseguir comida haciendo alusión a una práctica común de una población específica, los estudiantes y asistentes de eventos culturales. Tal población a la

${ }^{1}$ La palabra bajón también cuenta con las acepciones que hacen referencia al estado de ánimo como tristeza y al alimento consumido con el fin de bajar del viaje del consumo de drogas, sin embargo, aquí me ceñiré al uso de la palabra sólo en la acepción de alimento gratis. 
que refiero hace uso de la mesa dispuesta al final de los eventos (foros, coloquios, conferencias, inauguraciones, etc.) para sacar la comida sin tener que gastar o invertir en ella. Fenómeno que propongo es resultado del cruce de una precariedad en la que suele encontrarse el estudiantado y una viveza cínica para aprovechar lo puesto en gratuidad.

\section{El hombre ante el hambre}

El hambre es una de las experiencias de las que somos parte, el llanto de un bebé puede surgir en gran medida del trauma del afuera, de esa separación que se da; su primera condición de necesidad pues antes era proveído y ahora hay una distancia con el alimento. Así, el nacimiento como salida resulta un recordatorio del Körpe viviente que requiere una constante manutención: el alimento.

Derrida (2005) habla del comer como un bien necesario, es decir, el comer es algo que el hombre, desde su condición, no puede escapar ni prescindir: hay que comer. Pero también constituye un bien no moral sino político; representa la posibilidad de consumo y elección de lo que introyectamos, de aquello que seremos.

El hambre constituye el dato sensible y natural del hombre que posee un cuerpo y, al contrario de la tradición platónica, puede tomar el puesto de prima filosofía: remite a una de las pre-ocupaciones humanas fundamentales en su constitución. Es el pensar 'sobre' el cuerpo como un dar cuenta que poseo uno; el dato sensible del placer que me- produce o el dolor que hay en él; el arrastre hacia mis propias carnes como lugar desconocido y que se impone en la distancia de la abstracción que continuamente hago de un 'Yo', que subsume en partes una ilusión de tener conciencia de sí y el mundo que le rodea (Deleuze, 2004).

La alimentación es aquello que me mantiene, aquello que 'nutre'; da la fuerza al cuerpo, al cuerpo que soy yo, para alcanzar su máximo. Así, desde una postura material, las bebidas y alimentos son aquello que mantiene a lo que soy como hombre; sin ellos o con el exceso de estos mi ser hombre, generado en un principio por ellos, queda disgregado. Por este papel, la alimentación no puede quedar rezagada a una sola acción que se hace sin pensar, requiere de una técnica para saber jugar con los alimentos, o más, bien potenciando a nuestro favor.

\footnotetext{
¿Utilizo la palabra misión con un doble sentido: uno (1), resaltar las cualidades de la tarea diaria de conseguir el alimento - forma sigilosa y astuta como una misión militar-. Dos (2), hacer útil de la palabra misión como una forma coloquial de nombrar al conseguir alimento.
} 
Es con esto que el hambre se convierte en mi lazo fundamental con el mundo bajo la aprioridad cultural. Yo soy un cuerpo (carne) que por necesidad posee el hambre, sin embargo, también soy un cuerpo como experiencia que se encuentra con otros cuerpos. Además, sale al encuentro-consumo de los otros como un alimento que me afecta como bien, y potencia, o me deja impotente y vulnerable.

\section{Banquete}

En la historia de la filosofía hay varios banquetes, tal vez el más destacado y conocido sea el Banquete de Platón donde se discute sobre el amor y sus modalidades, según una búsqueda del bien y la belleza como fin del hombre. No obstante, también podemos encontrar otros banquetes donde la mística de la comida se hace presente. Para el presente artículo, tomo El Banquete de Jenofonte (2002) y El Banquete Sobrio (De Rotterdam, 2018) como complemento a la propuesta de un banquete cínico.

Un banquete puede entenderse como una congregación de hombres que a su vez disponen de comida. Impera el discurso después o durante como motivo de reunión; una especie simbólica de alimentarse del otro a través del despertar de los sentidos por la ritualista del anfitrión.

En el Banquete de Jenofonte, el discurso expone la kalokagathía como una búsqueda del Hombre. En él se presenta un Sócrates bailarín rompiendo con la idea de seriedad del personaje. Es la acción, la moción del cuerpo la que se impone en la búsqueda de la kalokagathía, "¿Os reís porque, teniendo demasiada tripa, quiero reducirla moderadamente?" (Jenofonte, 2002, p. 14) dirá Sócrates, convirtiéndose en un cuidador de sí, ante los otros.

También pone sobre la mesa la idea de la belleza como un bien que puede conseguirse bajo el trabajo. Sin embargo, la verdadera kalokagathía se consigue con el trabajo del alma; el philum de la amistad, donde los amantes se encuentran uno a uno, se desenmascaran desde lo mejor que tienen, así como desde su falta. Así, la kalokagathía se expone como una actividad gástrica erótica donde el hacerse consiste en un alimentarse (y un excretar) para sostener una comunidad buena y bella.

A su vez, El Banquete Sobrio habla de la comunidad, desde un ángulo distinto. En éste, la comunidad no será algo sostenido por los amantes sino una creación que surge. La convivencia de los reunidos y sobre todo su discurso, es lo que hace el banquete.

${ }^{3}$ Aquello que contiene en equilibrio lo bueno y bello. 
Cada convidado trae de sí un aporte; consiste en la forma en que alimenta su spíritu y cómo puede alimentar a los otros a través de lo que ha leído (De Rotterdam, 2018). Además, en la comunidad que emerge, lo más importante es la alimentación y no la comida, como un saber virtuoso de estar 'a tono' para reunirse.

\section{Banquete cínico}

"Son los heridos graves de la cultura los que con grandes esfuerzos encuentran algunos remedios curativos y hacen girar la rueda de la crítica".

Peter Sloterdijk

"Son los heridos graves, los de abajo y del desecho, los que con grandes esfuerzos encuentran algunos banquetes donde bajonear y hacen con ello girar la rueda de la crítica". Adaptación cínica de Sloterdijk

Para la propuesta del banquete cínico, tomo el cinismo (quinismo) desde la idea del desnudo y la búsqueda de la animalidad, tal como lo propone Peter Sloterdijk, donde el cinismo es el desnudamiento de las verdades frente a la cultura, donde lo real aparece como agresivo ante la mirada (Sloterdijk, 2003). Así, el banquete cínico sería un desnudo de la cultura que, al contrario de las propuestas de los banquetes antes vistos, no aspira a una perfección ni ejecución del hombre desde sus mejores maneras, sino desde la animalidad que es y su corporalidad.

En un banquete cínico, los convidados tendrían que convivir de algunas de las características del espíritu cínico (Sloterdijk, 2003, 38) estas son la extravagancia y solitud; la moral desde lo testarudo; lo mordaz; la malicia individualista; la mirada grosera y des enmascaradora y la inteligencia desclasada y plebeya.

\section{Extravagancia y solitud.}

El espíritu cínico cumple con la extravagancia, no porque haga uso de atavíos para ello, sino porque ante el ojo resaltaría su presencia, desde un no encajar o no tener lugar. Esto va aunado a la soledad, el cínico tiene por compañía a sí mismo.

\section{Moral desde lo testarudo.}

La moral que proscribe el espíritu cínico nace desde lo áspero de la testarudez. Es distinta a la moral del Banquete Sobrio, pues se encarna en práctica del filósofo como regla que se vive para poder comunicarse. 


\section{Mordaz.}

Al pensarse desde el individuo no existe un tinte para ablandar su lengua ante el otro. En cambio, el discurso debe hacerse desde el golpe desnudo. Este va de la mano de la mirada grosera; aquella que deja en cueros las maneras del otro escondido entre la aprehensión cultural, lo que deja otra vez al animal sin hogar.

\section{Malicia individualista.}

El cínico no piensa desde otro lugar que no sea el suyo. No come al otro ni se deja ser comido y se resuelve en la idea de bastarse a sí consigo, en una táctica caníbal.

\section{Inteligencia desclasada y plebeya.}

Este es uno de los puntos más relevantes, el espíritu cínico no es tonto, ve las cosas y trasfondo de ellas vacío. Su inteligencia no es fruto del cultivo y el Educere, sino de la sobra, de lo que queda por fuera, lo no visto y relegado a las calles. "La inteligencia de la que es provisto viene desde abajo, viene arrastrada de la letrina y los pelos que no habían querido verse en el cuerpo por haber puesto las puras y aseadas ideas" (Sloterdijk, 2003, p. 189).

Por su parte, El Banquete de Jenofonte no es un constante ejercicio a la virtud, o de lo propuesto por De Rotterdam. No es la lectura lo que lleva el cínico a los otros, sino su carácter plebeyo, incómodo ante la vista y a quien le huela.

Con esto en mente, puedo pasar al banquete ¿cómo sería tal banquete que permitiera tal carácter? Tal vez tendría que pensarse en la idea de un anti-banquete como fórmula de negación del ritual y prácticas ${ }^{4}$. No habría una predisposición del banquete; se tomaría por asalto la ocasión donde se diera la reunión del cínico y la comida. El anfitrión no sería aquél que pone las viandas y escoge su disposición, sino aquél que invita al disfrute de las viandas.

Por último, el discurso que acompañaría el banquete sólo podría ser aceptado en tanto surja como sobra y como cuerpo. En cuanto sobra como aquello que no ha sido digerido por la 'civilidad y la cultura' sino que le pertenece a quién lo dice. Como cuerpo, en tanto que tendría que manifestarse en la carne de aquél que habla, un acto viviente que se habla. Es la animalidad del cínico lo que constituirá su discurso, su estilo desnudo y des amanerado lo que le hará un convidado del banquete (Sloterdijk, 2003).

${ }^{4}$ Aquí hago un guiño con la práctica del perfumarse y bañarse antes de acudir a un banquete, para ser 'adecuado' ante la invitación. 


\section{El bajón visto como banquete cínico}

En una ocasión en que se le preguntó a Diógenes qué vino le gustaba más, respondió: "El ajeno" (Laercio, 2004, p. 196). Así, brinda una idea del disfrute o plus que trae la vianda que no nos ha costado; a la que se llega como perro a beber, en tanto que está dispuesta. Entonces, el bajón desde la búsqueda de comida gratuita puede tomarse como gesto cínico y como plus que conserva la alegría de la composición con la comida, de aquello que me dan. En la idea de ajeno, de lo no trabajado por mí, que asoma el espíritu del individualista; además la gratuidad puede ser vista desde la idea de un don, la comida un donar por el otro: lo externo hacia mi necesidad fundamental, lo interno.

Como se menciona en anteriores párrafos, el hambre es el principal dato sensible de mi cuerpo; aquél con el que tengo que hacérmelas como animal precario; existe un hambre en mí a saciar con algo también material, no puedo decir que sacio mi hambre simbólica, virtuosa o de forma epistémica, o al menos no sólo así. "¡Ojalá que frotándome el vientre no tuviese hambre!" (Laercio, 2004, p. 193). Sin embargo, la necesidad de alimento persiste a nuestra completitud animal, es decir, no contamos con herramientas (manos en caso de la masturbación) para saciarla, hay que hacer uso del externo para llenarla. Así, el bajón que busca el sujeto precario, es un bajón desde lo material que le sirva para lo material -körpeque se le da en los borborigmos como dato de necesitante, de algo que persiste y dice estar ahí.

Acerca de la inteligencia desclasada del espíritu cínico, también puede entrelazarse con el bajón en busca de lo gratis, puede ser la reunión con conferencias, exposiciones etc., lo cual sería el conocimiento limpio y puro de la cultura. No obstante, ante el cínico que desea bajonear en él, sólo cabría el mordisco que 'pela' la verdad, por medio de ejercer una verdadera crítica de lo 'expuesto'. Además, como perro aprovecha los platos descuidados por los conservadores del arte para comer, alimento que le está prohibido y que no está específicamente dispuesto para quién bajonea, sino quien ha pagado con forma y civilidad por ello.

\section{Posibilidades de una comunidad en el banquete cínico}

Si bien una de las características del espíritu cínico es el de la individualidad, posee algunas cualidades. Así, el yo individualista del cínico es "un yo político que piensa en primer y último término en sí mismo, que interiormente transige, 
y exteriormente se acoraza" (Sloterdijk, 2003, p. 16). Además de ser un yo como zoon politikon; el que llega a bajonear desde el cinismo está operando desde una animalidad que quiebra las maneras de lo civil (Sloterdijk, 2003).

Con esto dicho, podría gestarse la idea de comunidad dentro del banquete cínico; sería desde un eje político como resistencia al hombre como idea, como pureza de estilo y manera. El cínico que llega a donde hay un banquete dispuesto y no oculta su hambre, es decir, que al decir la verdad de su cuerpo se desnuda ante los otros, es un cínico que bajonea libre, sin vergüenza. Durante el encuentro con un otro cínico libre y desnudo, puede gestarse una comunidad, no como un compartimiento de alimentos, sino desde el posicionamiento de un lugar común, su fundamental carencia y lucha de vida. Tal comunidad no es duradera, ni gesta por el bien del otro, sino que se posiciona y toma lugar ante los otros, se deja ver u oler como inversión material que recuerda para sí y su -público- que hay que comer, y qué mejor que lo ajeno.

\section{Referencias bibliográficas}

Derrida, J. (2005). Hay que comer o el cálculo del sujeto. Confines, (17)21. Recuperado de: https://www.jacquesderrida.com.ar/textos/comer_bien.htm\#_edn2

De Rotterdam, E. (2018). "El banquete sobrio". En Los Banquetes. Madrid: La oficina.

Gilles, D. (2004). Spinoza, Filosofía práctica. Argentina: Tusquets.

Jenofonte. (2002). Banquete. Madrid: Gredos.

Laercio, D. (2004). Vidas de los filósofos más ilustres. México: Tomo.

Sloterdijk, P. (2003). Crítica de la razón cínica. Madrid: Siruela.

\footnotetext{
${ }^{5}$ La crítica a la que refiero es la propuesta por Sloterdijk (2003), La crítica «realiza» un movimiento que en una primera instancia agota sus intereses positivos y negativos en la cosa, para, finalmente, chocar contra las estructuras elementales de la conciencia moral, estructuras a las que se obliga a hablar «más allá del bien y del mal».
} 